\title{
Managing ice walls and other operational challenges while optimising Victor Mine late stage opportunities
}

\author{
M Rougier Golder, Canada \\ PJH de Graaf Anglo American, De Beers Group of Companies, Australia \\ M Desjardins De Beers Canada, Inc., Canada \\ M O'Leary Mount Polley, Canada (formerly De Beers, Canada) \\ N Yugo Independent Consultant, Canada (formerly De Beers, Canada) \\ B Kilbride De Beers Canada, Inc., Canada
}

\begin{abstract}
This paper discusses the engineering, hydrogeology, operational practices and TARPs that facilitated deeper mining and goodbye cuts at the De Beers Canada Victor Diamond Mine. A number of technical challenges related to water management and adverse geology late in the mine life were overcome in order to successfully meet and exceed the planned mining depth. Extensive pit dewatering and a pit water management program were implemented not only to maintain dry working conditions for operations but to ensure highwall stability and reduce the formation of hazardous ice columns along the highwalls. After a $15 \mathrm{~m}$ tall ice column failure, bench design was optimised to ensure perched aquifers occurred as low on the highwall as possible. Where the uppermost ice columns formed, strategic reinforced meshing was installed to eliminate the possibility of sudden ice column failures that could not be predicted with the monitoring systems in use. Excellent limits blasting outcomes and better than expected conformance to design also allowed for inter-ramp limestone slope optimisation. Additionally, a 'ploughing' style failure mode was of concern due to blocky limestone underlain by saturated clays and mudstones. Here, a pit redesign and highwall depressurisation thresholds were used to prevent this failure mechanism from occurring, as well as developing vibrating wire piezometer trigger action plans. The overall results of the integrated hydrogeological and geotechnical designs and slope management practices were positive and contributed significantly to slope design optimisation and safely recovering additional ore. What worked technically and in terms of people and procedure are shared.
\end{abstract}

Keywords: TARP, trigger action response plan, ice, icefall, mesh, slope depressurisation, slope optimisation, blasting, goodbye cut, slope stability, Severn, Red Head Rapids, Attawapiskat, sump, Hudson Bay Lowlands

\section{Introduction}

The feasibility stage Victor Mine Open Pit mine plan involved exploiting kimberlite pipes intruded into horizontally bedded limestone formations of the Hudson Bay Lowlands in northern Ontario, about $90 \mathrm{~km}$ east of the first nations community of Attawapiskat. Mining began in 2008 and ended in 2019. The datum reference for the Victor pit is the $100 \mathrm{~L}$, which is ground surface, at $80 \mathrm{~m}$ above sea level. Depth is positive downwards. The next bench, at $60 \mathrm{~m}$ above sea level, is the $120 \mathrm{~L}$ bench. A feature on a bench face, elevation $-58 \mathrm{~m}$, would be at level 238B.

Positive slope performance and lessons learned at the De Beers Canada Victor Mine led to slope optimisation studies in 2011-2012. These slope geometry, dewatering and operational practices allowed the pit to be safely deepened by over $60 \mathrm{~m}$ within the existing footprint. This optimisation extended the mine life to Quarter 1, 2019. However, the deepening extended slopes into weaker shale formations and potentially exacerbated the dewatering, ice and stability challenges currently being managed. In 2015 and 2016, the 
geotechnical, hydrogeological and operations teams collaborated to develop the mine plan and tactics to safely mine.

Several technical challenges related to water management and adverse geology late in the mine life were overcome in order to successfully meet and exceed the planned mining depth. Extensive pit dewatering and a pit water management program were implemented not only to maintain dry working conditions for operations but to ensure highwall stability and reduce the formation of hazardous ice columns along the highwalls. This paper discusses the engineering, hydrogeology, operational practices and TARPs that facilitated deeper mining and goodbye cuts at the De Beers Canada Victor Diamond Mine.

\section{Geotechnical setting and opportunity}

The feasibility stage Victor Mine Open Pit mine plan involved exploiting kimberlite pipes intruded into horizontally bedded limestones of the Attawapiskat, Ekwan and Severn Formations (youngest to oldest). Permafrost was encountered only in small pockets within the clay overburden which was up to $20 \mathrm{~m}$ thick clay. The upper limestone aquifer had high horizontal conductivity and recharge requiring sumps and perimeter dewatering wells to manage inflows. Experience with the early limestone slopes justified steepening with double benching, vertical pre-shear and wall control scaling. The steeper bench geometries developed from 2012 to 2016 and shown in Figure 1, allowed the deepening by 60 to $70 \mathrm{~m}$.

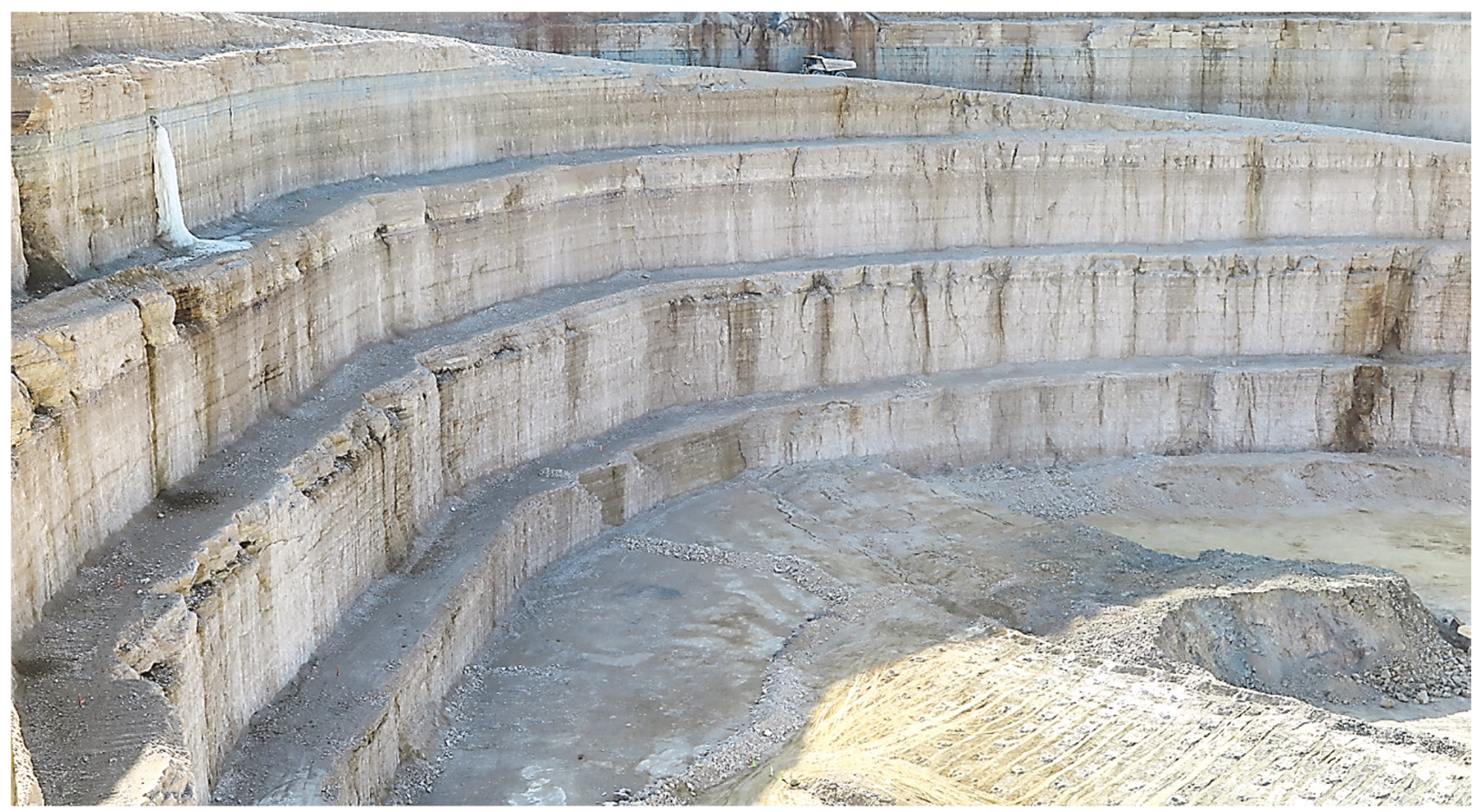

Figure 1 Excellent bench results 2016 provide flexibility to the mine plan for the deepening

This deepening required new operational tactics because the deeper slopes would expose weak to very weak shales and calcareous sands beds over a vertical interval of $30 \mathrm{~m}$, which was a contrast to the strong overlying limestones.

Wider benches were required to manage back-break, sloughing and erosion of the weaker shales. The bench levels needed to be close and just below targeted beds that seeped, so that the water could be channelled properly. The excellent slope performance and steepening of the overlying Severn limestone allowed bench height and width adjustments to be made without reducing recovery of ore. The result was single bench heights of $14 \mathrm{~m}$ through the weak and very weak country rock shales of the Red Head Rapid Formation (RHR). The stratigraphic column, the exposures of the RHR shales in plan view and the collars of the geotechnical holes are shown in Figure 2. 


\section{COUNTRY ROCK STRATIGRAPHY}
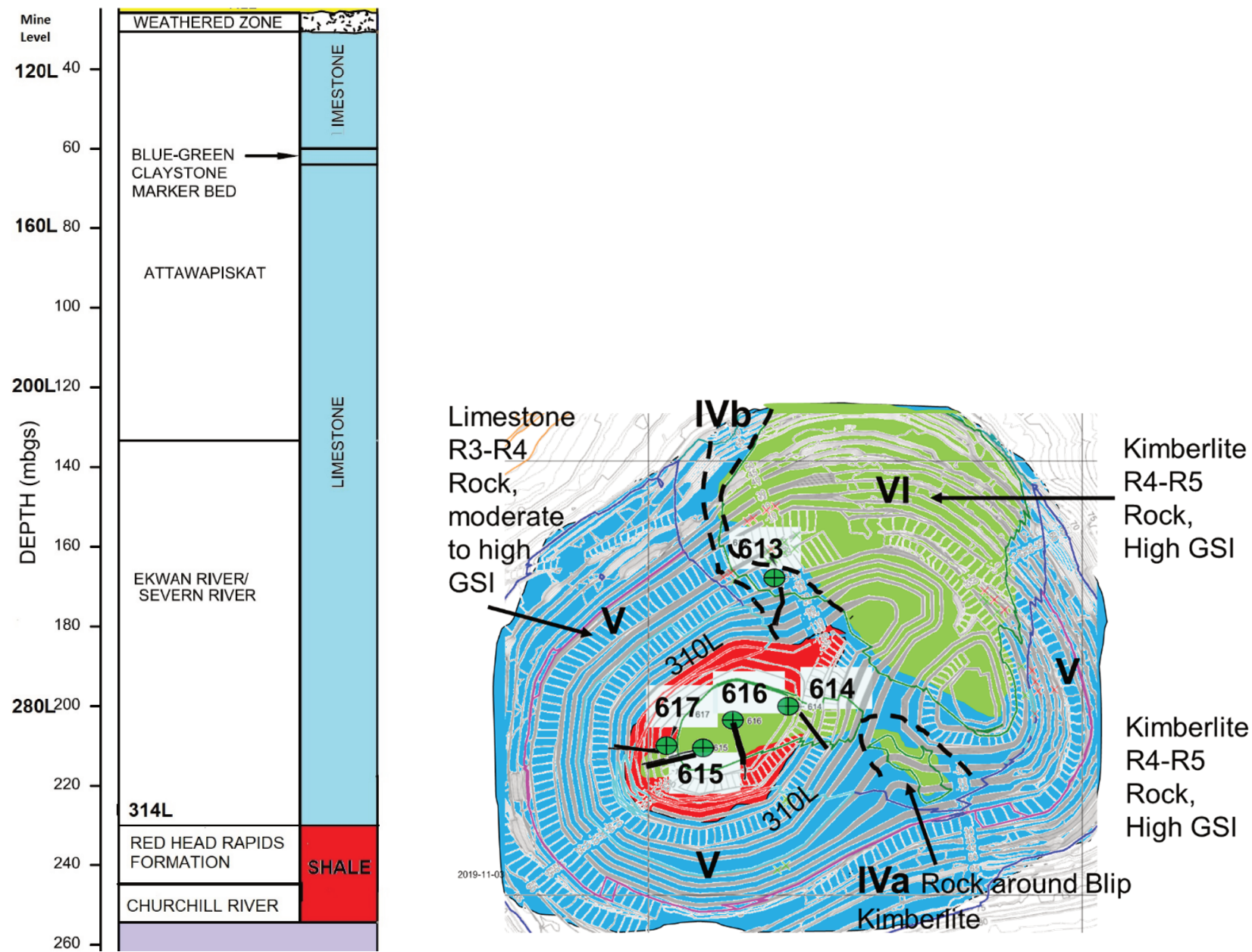

Figure 2 Stratigraphy column and final pit shell showing limestone, kimberlite and Red Head Rapid Formation shale exposure

\section{$3 \quad$ Northern challenge}

\section{$3.1 \quad$ Ice}

Ice formed on bench faces at Victor Mine, which is a typical challenge for mines with seepage and below freezing temperatures. The perimeter and in-pit dewatering wells cannot intercept all seepage along bedding. This residual passive inflow (RPI) results in ice build-up on bench faces.

During the winter, the ice accumulation was a nuisance and production was delayed. Ice build-up would encroach on the ramp width and required regular scaling and hauling out of the pit. However, during spring freshet (melting of accumulated snow and ice), rockfall and icefall increased greatly spring when the ice columns would begin to thaw. The melting water would flow along the highwall and melt the columns from behind, detaching them from the highwall creating a toppling risk. For areas within excavator reach of the main ramp, the ice was mechanically scaled down.

In areas out of reach of scaling equipment, the ice columns and ice fall were managed with mesh. Initial icefall mesh installations were draped to prevent to ice columns from toppling outward onto the ramp or mining areas below. However, as shown in Figure 3, the weight of ice and ice at the toe caused ravelling rock to bag in the mesh, tearing the mesh or overloading the anchors. The mesh performed best when anchored away from the toe, as shown in Figure 4. 


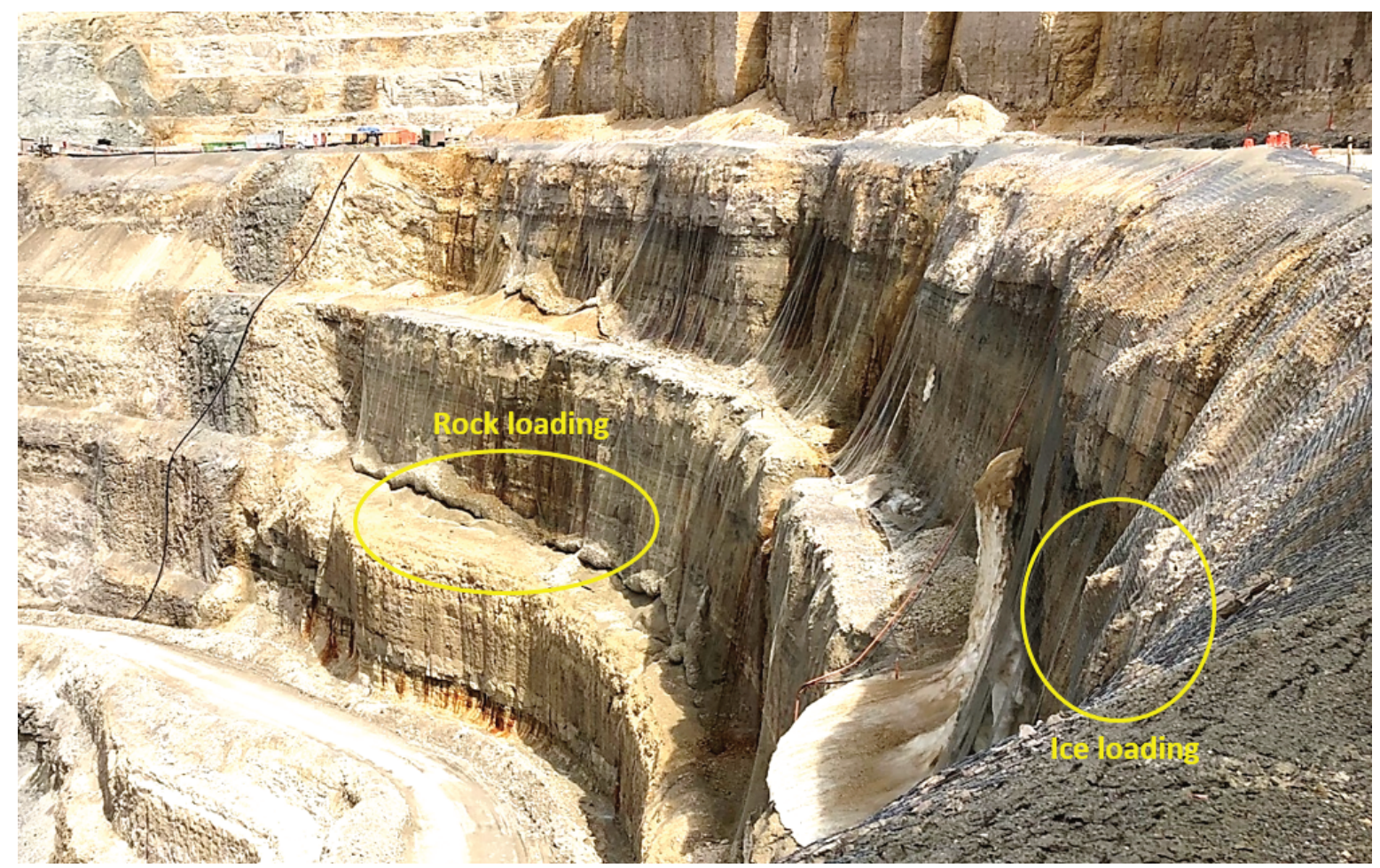

Figure 3 Ice and rock accumulations add loading that bends anchors and tears the draped mesh

Hazardous Ice columns in areas that had not been meshed were barricaded until the ice would melt. However, if this was delaying production the operation tried to speed up melting with water sprinkler systems. Operations tried having highwall scalers place explosives behind the ice columns. Both methods had only limited success.

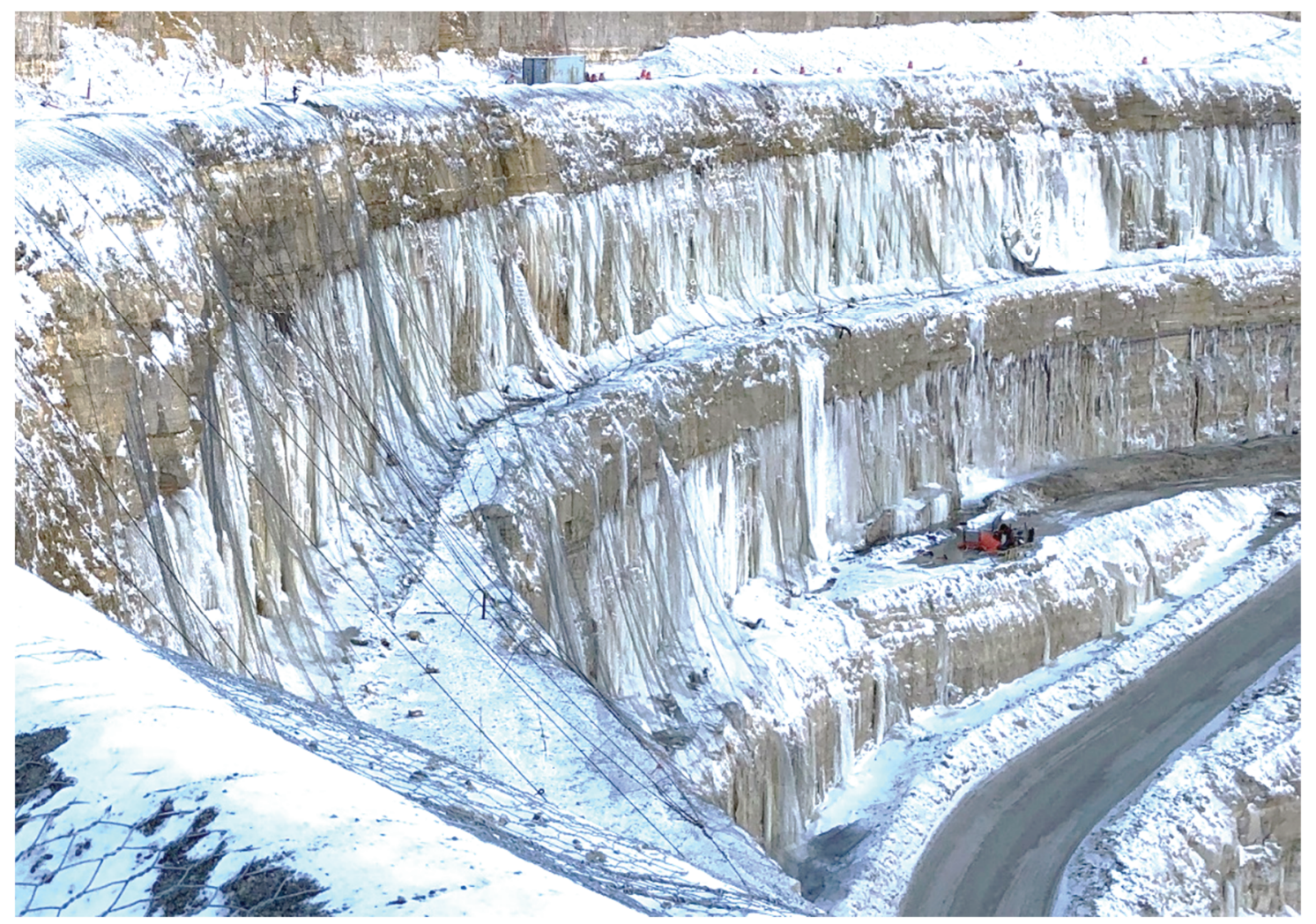

Figure 4 Mesh for ice performed better when anchored away from the toe 
In December 2016, a low-flow RPI at the $238 \mathrm{~B}$ level resulted in an $80 \mathrm{~m}$ long and $15 \mathrm{~m}$ high ice wall. The build-up of ice resulted in bench scale toppling failure. This event contributed an additional slope design criterion to the optimisation: where feasible wider benches should be incorporated into the design to intercept RPI seepage. The mine team was open to deviating from standard $10 \mathrm{~m}$ single and $20 \mathrm{~m}$ double benches where this would improve slope performance and water management. The $80 \mathrm{~m}$ long ice wall is shown in Figure 5.

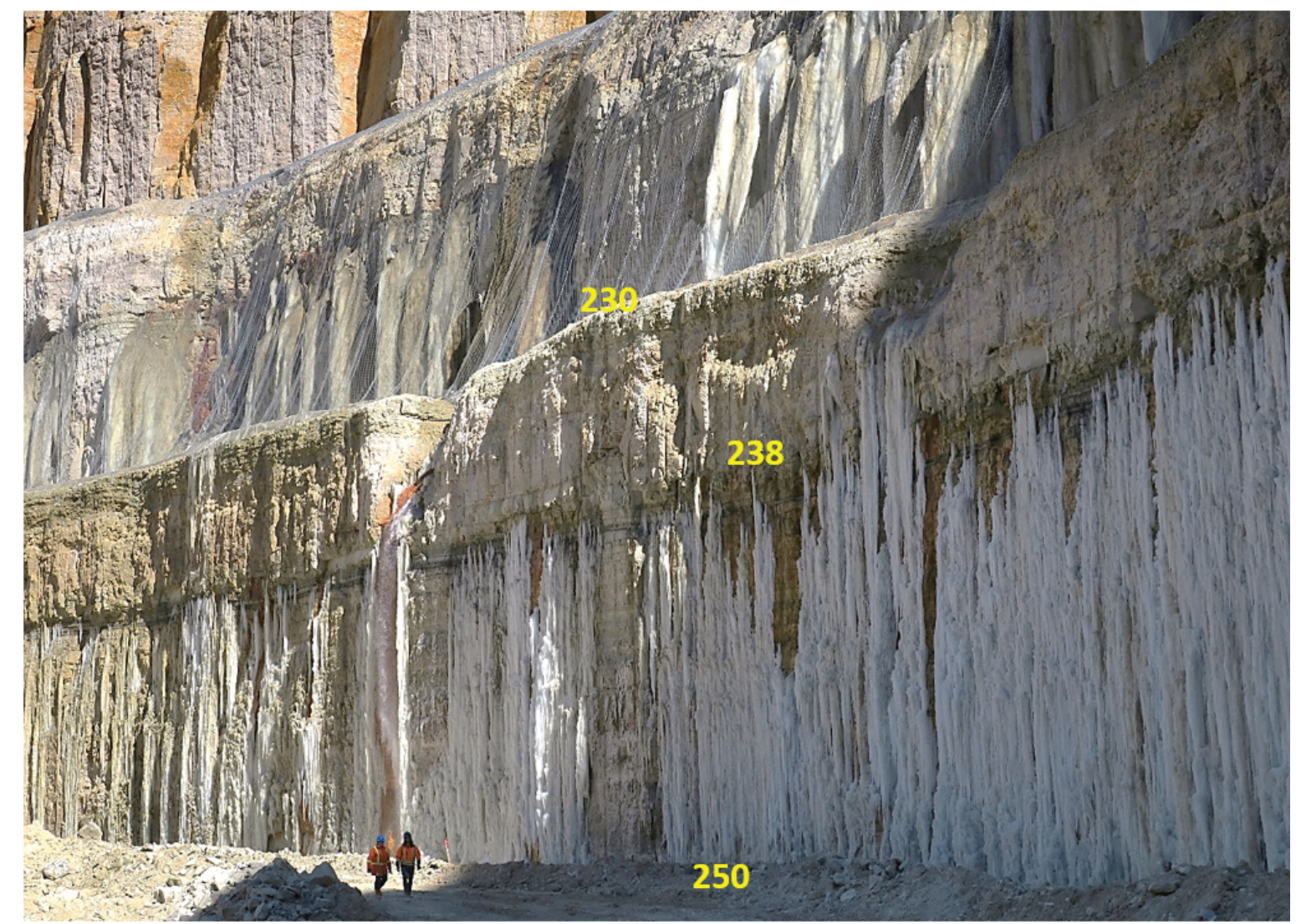

Figure 5 Victor Southwest ice formation $58 \mathrm{~m}$ below sea level, mine elevation 238

\section{$4 \quad$ Slope design optimisations}

\subsection{Mining through the limestones and shales}

The hydrogeological review and drilling results indicated that the key location for a wider, dual-purpose hydrogeological and geotechnical bench was the contact between the Severn and the RHR, at elevation 314B. The team incorporated $14 \mathrm{~m}$ high single benches above and below this contact, with variable bench widths, for this purpose.

Ultimately a $6^{\circ}$ improvement in inter-ramp angle (IRA) was realised in the final three Severn Formation benches $\left(61^{\circ} \rightarrow 67^{\circ}\right)$ by reducing design berm width by $2.5 \mathrm{~m}$. The design optimisation had several benefits:

1. Capitalised on excellent slope performance and lock in upside potential.

2. Flexibility to step out later to address 'unforeseen' issues.

3. Provide additional space and depth for optimised ore recovery.

The achievable bench face angle in the RHR shales was a constraint. To optimise the slope design through the shales, $14 \mathrm{~m}$ single benches were also used. Below the 341B level, slopes were entirely in competent kimberlite. The profile optimisation, integrating water management, icefall and diamond recovery controls is shown below in Figure 6 . 

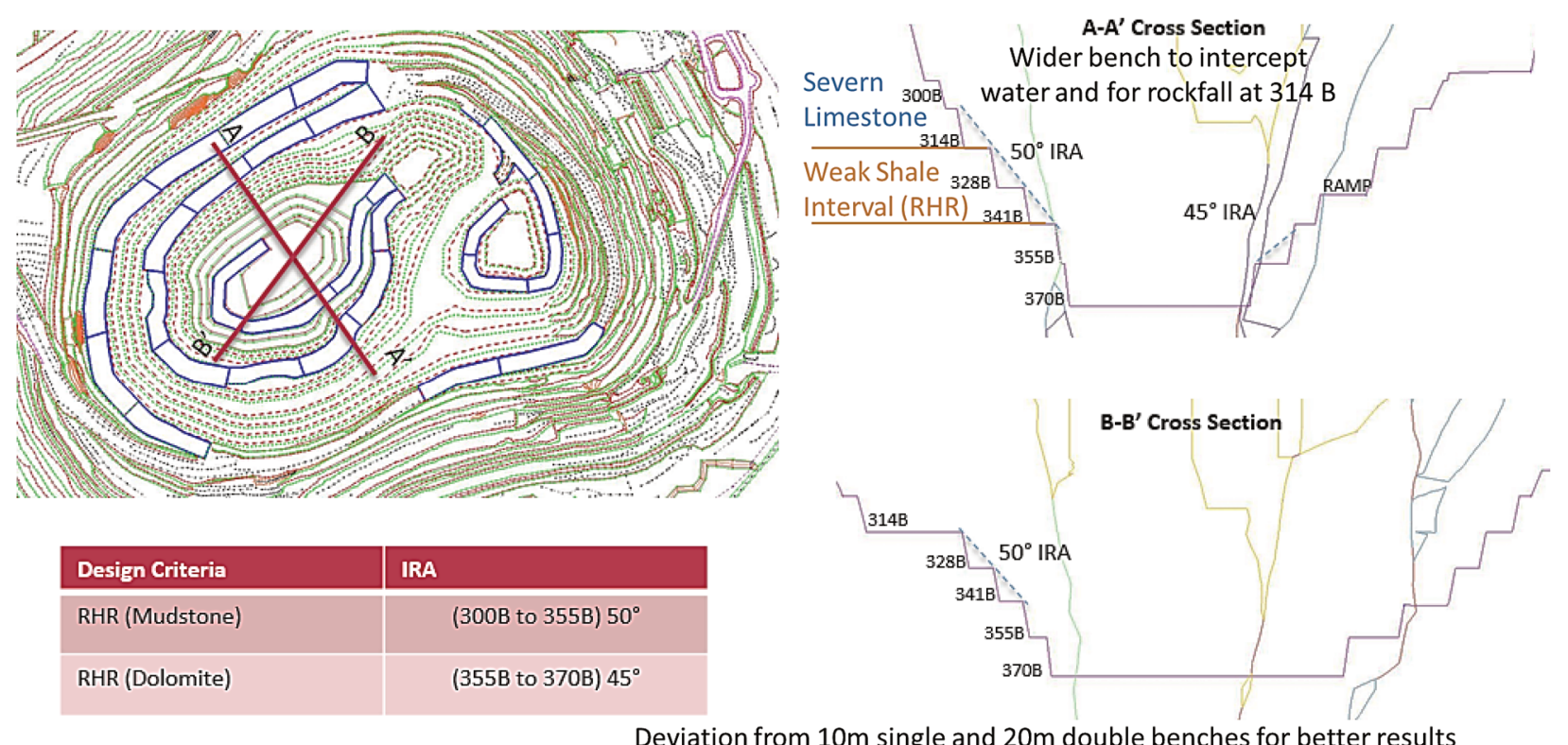

Figure 6 Optimised Victor Southwest bench geometry

\subsection{The 2017 and 2019 Victor goodbye cuts}

Once mining was below the shales, the pit bottom and ultimate benches bottom would only expose competent kimberlite, which would be the Goodbye cut. Learnings from the 2017 Victor Main South goodbye cut were incorporated into the Victor Southwest goodbye cut. The goodbye cuts locations are shown as purple in Figure 6. Figure 7 shows dimensions and full extraction of ore from the cut. This section focuses on the Victor Southwest goodbye cut.

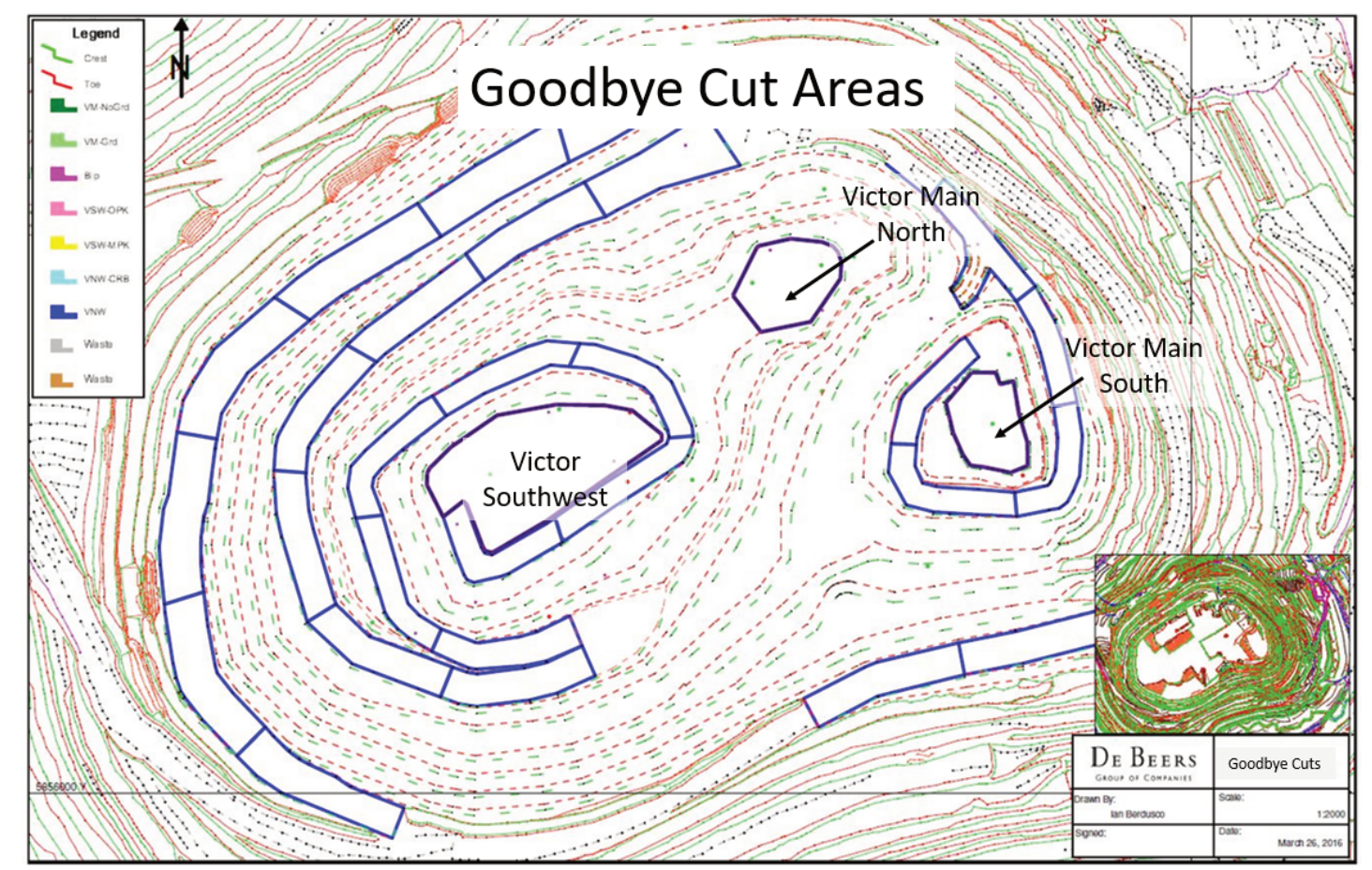

Figure 7 Three goodbye cut areas

The footprint of Victor Main South goodbye cut is approximately $66 \mathrm{~m}$ by $42 \mathrm{~m}$; which was not enough space for the standard CAT992 loader and CAT777 trucks to operate effectively. A CAT385 excavator and CAT735 trucks were utilised instead. The Victor Main South geometries are shown on Figure 8. 


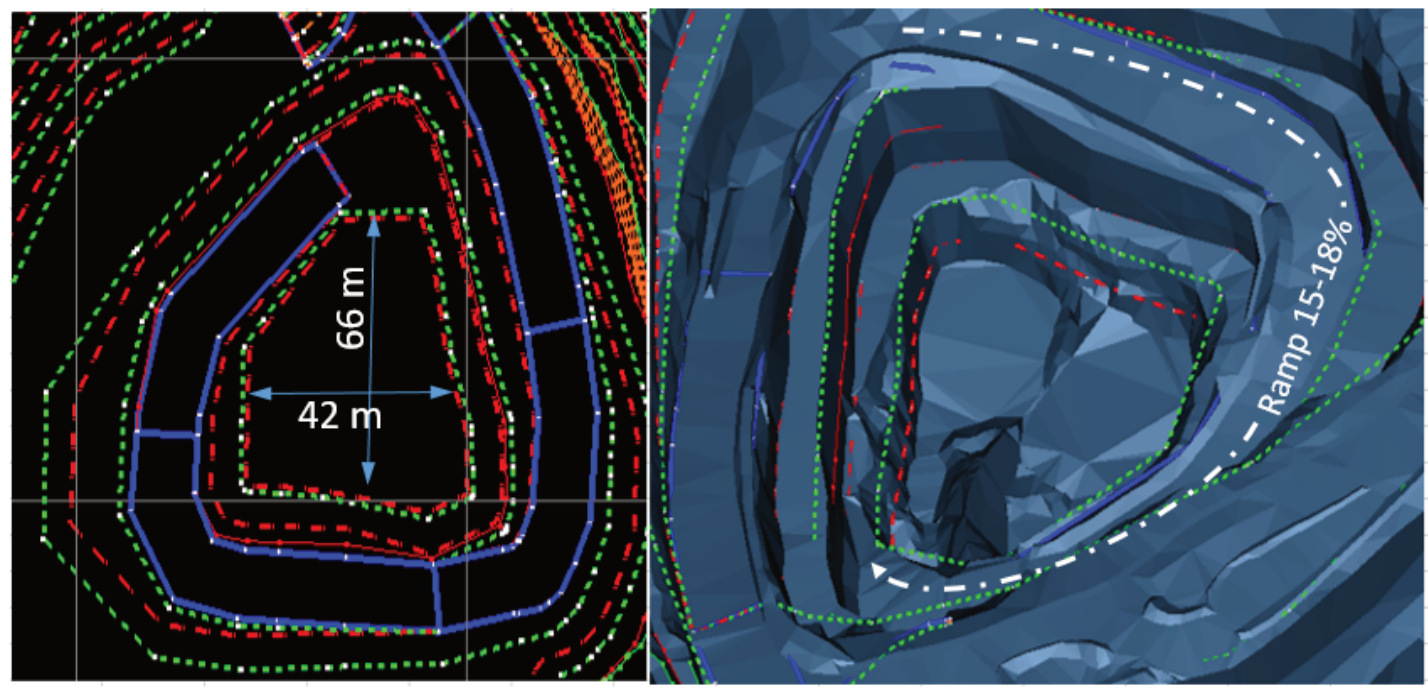

Figure 8 Victor Main South goodbye cut dimensions

The drill and blast design follows the precision blasting method developed by Dr Calvin Konya. The method determines the burden based on the relation of rock and explosive densities, and the diameter of the explosives used (Equation 1):

$$
B=0.012\left(\frac{2 \rho_{e}}{\rho_{R}}+1.5\right) \times D_{e}
$$

where:

$$
\begin{array}{lll}
\mathrm{B} & = & \text { Burden. } \\
\rho_{e} & = & \text { Density of the explosives. } \\
\rho_{R} & = & \text { Density of the rock. } \\
\mathrm{D}_{\mathrm{e}} & = & \text { Diameter of the borehole. }
\end{array}
$$

As the pattern is square, spacing is determined with the same formula. The first holes to fire in the pattern deliver a heavy concentration of energy. For this reason, the subdrill is half of the burden, and the collar (depth of stemming material from top of hole) is the full length of burden. All other holes have subdrill of $30 \%$ of the burden and a collar of $70 \%$ of the burden and are sequenced to blast into the void created (Konya 2006). The maximum hole depth of $20 \mathrm{~m}$ was determined by testing hole caving integrity prior to finalising a drilling design. Holes were continuously dipped/surveyed to determine maximum possible open hole drill depth.

Mining was completed in two $10 \mathrm{~m}$ lifts, with the ore ramp retreating out as steep as possible as a grade of $15-18 \%$. Scaling the wall using a CAT385 whilst progressing deeper into the cut was imperative to ensure safety for the operators in the tight footprint.

When the maximum extraction was achieved using the ore ramp, waste material from Cut- 2 was hauled and backfilled to establish a new waste ramp. This allowed for the extraction of the ore ramp and produced a total recovery of $83 \%$ of the goodbye cut.

\subsection{Slope depressurisation trigger response plan for the optimised pit}

For planning and for safe mining purposes, the agreed worst-case failure mechanism for mining through the Severn Limestones and RHR shales involved failure through weaker shale layers combined with sub-vertical release planes. The mechanism was sensitive to water pressure in the shales. To assess whether mining the next bench was permissible, the limit equilibrium Factor of Safety (FoS) results were plotted at key vibrating wire piezometers installations. The hydrograph for Multi-Level Vibrating wire piezometer V-16-632 is shown in Figure 9 and taken from Rougier \& Smith (2017). 
The rate of mining, bench by bench versus time, is presented as a purple line on the hydrographs. The associated limit equilibrium FoS for the failure mechanism and trigger action response plan (TARP) are presented in three categories:

- Category 1: FoS >1.3 - no concerns.

- Category 2: $1.1<$ FoS <= 1.3 - continue mining however slope movement monitoring systems must be functional.

- Category 3: FoS<= 1.1 - risk assessment, stability analysis and other remedial measures need to be carried out prior to deepening.

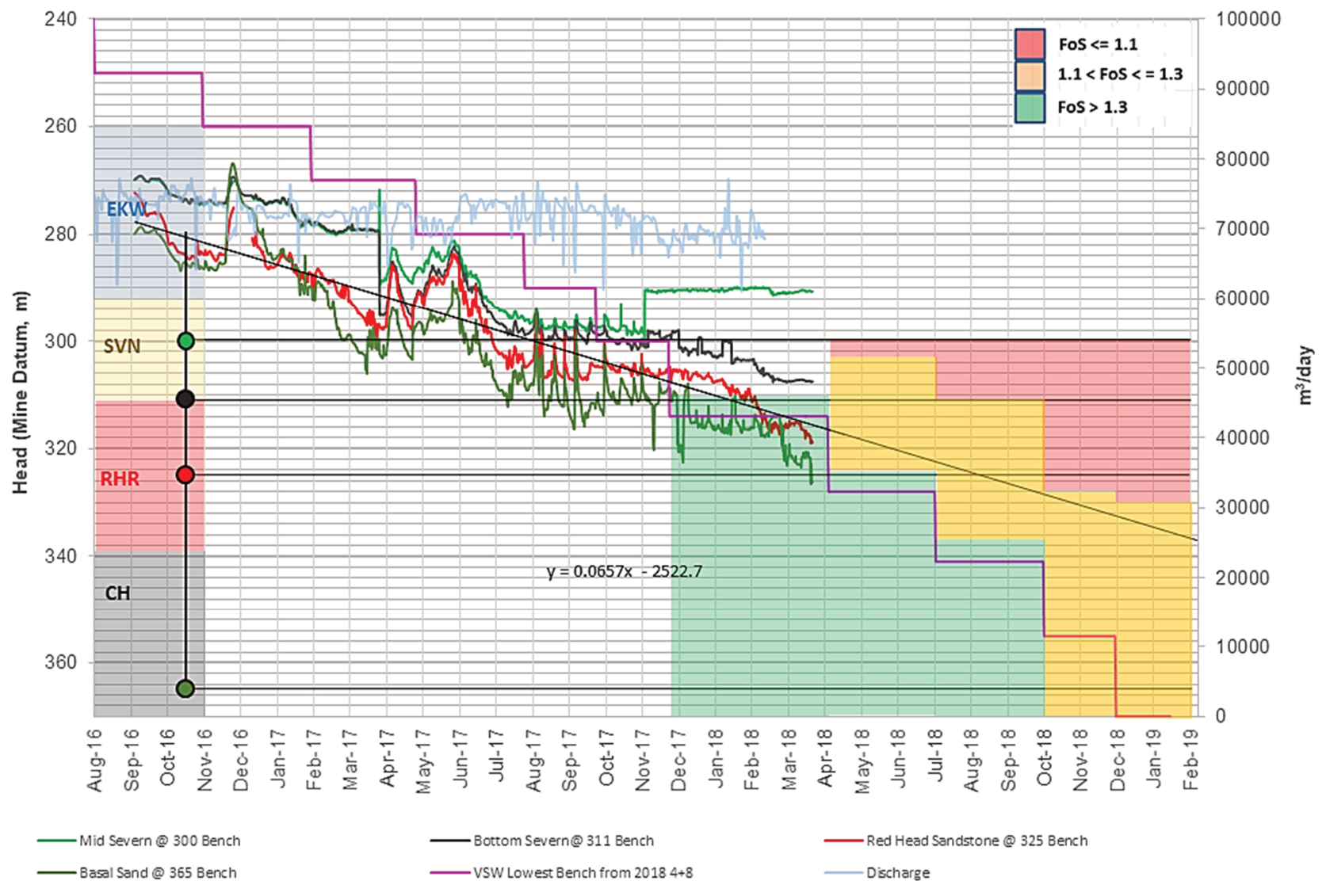

Figure 9 Example target dewatering thresholds for continued mining (after Rougier \& Smith 2017)

Given the hydrogeological setting, the most likely remedial measures would have been:

- Wait for the perimeter and in-pit wells to bring the drawdown to the target (sub-optimal); or

- Enhance the depressurisation with horizontal drains.

No such remedial measures were required. The dewatering/depressurisation readings and trend remained within acceptable Categories 1 and 2.

\subsection{Optimisation conclusion}

The outcome of all the studies and analysis produced a final design which improved pit stability, reduced business risk and ensure adaptive management was achievable. The adaptive management approach involves the continuous monitoring of mining conditions coupled with changes to engineering design criteria as required. For example, angles would be made shallower where the rock mass was performing poorer than expected due to water, lower Geological Strength Index, etc. The steeper IRA on the limestone highwalls, 
steeper ramps, diligent dewatering management and learnings gained in the goodbye cut trial allowed for higher than expected recovery of carats. Ore recovery was about $15 \%$ above the feasibility study forecast.

\section{$5 \quad$ Possible improvements and lessons learned}

\subsection{Mining deeper}

Initial mine plans included an ultimate mining depth target to about the 330 bench. The planned ultimate depth was successively increased as mining indicated good wall conditions and better than expected economics. One year prior to mine closure, a final bench at the 350 horizon was planned with a $15 \mathrm{~m}$ goodbye cut down to 365 bench. The scavenger bench was budgeted as $75 \%$ recoverable.

During the last few months of mining, the plan was once again altered based on positive economic, stability, and dewatering performance. The final bench design was altered to 375 with an option to drill a scavenger bench to 390 or beyond, depending on ground and water conditions. This uncertainty was difficult to reconcile with the logistical and operational planning activities associated with equipment phase-out and the reduction of the workforce.

Once the 375 bench was reached, ground and water conditions indicated that the risk and challenges of mining deeper would not have been in excess of those from the previous bench. A hard stop was anticipated to be triggered by freshet conditions that were expected to cause ice and material movements down slopes, which at this point would have been almost $100 \mathrm{~m}$ deeper than experienced during the previous freshet. To make the area safe after freshet would have delayed last ore mining and closure by up to six weeks. Although the costs for rope access scaling and additional rockfall mesh would have been small in relation to ore recovery, the camp (remote living facilities including working, sleeping, recreational and dining facilities) and incidental costs outweighed the opportunity for mining a few additional weeks.

As the exact date of the start of freshet is weather dependent, it was a scheduling unknown and by the time it was determined that mining could likely proceed at least $15 \mathrm{~m}$ deeper, reductions in the workforce and progression of the closure plan made this operationally impractical. Goodbye cut ore was treated as an opportunity and not $100 \%$ relied on in the mine schedule, a flexible weather plan was implemented which allowed an extra week of ore production to be achieved (than initially planned), but ultimately the hard stop was governed by the need to safely remove pit bottom dewatering infrastructure before freshet and initiation of closure activities.

In hindsight, the production schedule should have been flexed such that the end of mining did not coincide with freshet. This would have allowed for simple economic opportunity trade-off to manage technical uncertainties (such as geotechnical and hydrogeological conditions) and provide incentives to flex employment contracts, rather than be constrained by the vagaries of weather and a significant potential balloon cost and safety risk at the tail end.

\subsection{RPI water management system}

In consultation with Piteau Associates, the Victor Mine considered the implementation of horizontal drain holes with the aim of depressurising high walls. The initial evaluations for the program were from the 300 bench down based on using the observational method. As mining progressed beyond 300 to the ultimate 375 bench level, piezometer readings and wall conditions were monitored. These confirmed that excessive porewater pressures were not building behind the slopes and the inflows did not pose a stability risk.

The observational method worked well in that the mine plan was continuously adapted in anticipation of a possible horizontal drain hole drilling campaign but was able to utilise the upside. As each successive bench was mined and it was determined the horizontal holes were unnecessary, production was able to utilise available resources to accelerate mining in lieu of drilling.

In addition to the drain holes, a water reticulation system was envisaged whereby drain water would be channelled to a pumping system rather than allowed to flow over the crest. This was studied as a 'packaged' 
approach with the drain holes and was therefore never fully implemented as a standalone solution. As mining progressed, it became evident that water flow, from both RPI and weather events, was detrimental to the stability of the bench crests in the RHR clay layer. While this did not pose a risk of deep-seated multi-bench circular failure mechanisms, it did complicate mining. The smaller scale failures and rockfall necessitated the implementation of exclusion zones limiting access to areas near the walls. In order to mitigate this risk, real-time radar critical monitoring and alarming in conjunction with Riegl laser scanning and dynamic offlimits regions were utilised.

Towards the last few weeks of mining, water in one region of the 300 bench areas was successfully channelled to a well/sump hybrid complete with a small settling pond to control sediments as well as an overflow pipe. This approach greatly reduced the progressive ravelling and erosion of the RHR clay crests once implemented.

In hindsight, a water reticulation system would have had the potential to greatly enhance the crest stability of the weaker RHR clay units and may have prevented the need for extensive operational controls and monitoring required towards the end of mine life. Where practicable, water could have been channelled via ditches to nearby wells. Alternatively, the catchment benches may have been designed with tangential gradients of between $1-2 \%$ with ditches to control the location of surface water collection and pump or otherwise direct it away from vulnerable clay crests.

The key learning here was that it may be beneficial to study different components of an engineering strategy both as part of the larger system, but also assess to the solutions independently on their own merits as part of individual engineering strategies.

\subsection{Earlier rigorous slope reconciliation}

While the slope performance evaluations started in 2010 and the slope optimisation work carried out in 2011 through 2016 extended the mine life, earlier implementation of rigorous slope reconciliation and communication strategies might have led to more aggressive designs. For example, the limestone benches could possibly have been excavated as $15 \mathrm{~m}$ single and $30 \mathrm{~m}$ double benches, for additional slope steepening earlier in the mine life.

\section{Conclusion}

The mine successfully overcame significant hydrogeological and northern climate challenges. This included managing ice walls and ice fall hazards with mesh and operational controls. The limestone slopes were able to be steepened, allowing for modified bench geometries in the shales that addressed geotechnical concerns, provided additional berm width for water management and diverted water using novel solutions such as a well/sump hybrid. Slope depressurisation concerns were managed with clear trigger threshold targets at important vibrating wire piezometer locations linked to mining elevation and FoS. In hindsight, further operational optimisations could have been possible to demonstrate that there is always room for improvement. Optimisation ideas on design improvement, on the management of the passive seepage and on earlier slope reconciliation were also shared.

\section{Acknowledgements}

The authors thank De Beers Canada for allowing this paper to be shared. We thank Geoff Beal at Piteau, the technical hydrogeological lead. We thank the De Beers Victor Mine team, without whom none of this could have happened. All opinions and conclusions drawn in this paper are those of the authors alone and it should not be assumed that any views expressed herein are also necessarily those of De Beers or Anglo American.

\section{References}

Konya, CJ 2006, 'Rock Blasting and Overbreak Control', International Society of Explosives Engineers.

Rougier, M \& Smith, J 2017, Development of Piezometer Dewatering Targets for the Victor Mine Ultimate Pit Slope Designs, Golder Associates Ltd, De Beers Canada Victor Mine, pp. 29. 